\title{
Design informacional de embalagens de café: uma análise dos elementos visuais e informacionais como identificação de conteúdo
}

\author{
Camila dos Santos Vieira ${ }^{1}$; \\ Erika Veras de Castro $^{2}$; \\ David Guilhon ${ }^{3}$;
}

Carmem Helena Ribeiro Maciel ${ }^{4}$;

\begin{abstract}
resumo:
O propósito deste documento é apresentar as variações de comunicação visual do design na atualidade, em relação às embalagens, e o quanto isso pode favorecer positivamente para o consumo de um produto, bem como sua importância em termos de mercado, com enfoque ao produto café. Nesse trabalho, será abordada uma metodologia conhecida na área do no design da informação, afim de analisar como os elementos visuais e informacionais geram identificação de conteúdo por parte das embalagens. Durante o processo, foram realizadas coletas de embalagens nos supermercados locais, as quais foram organizadas e analisadas por tipo do produto.
\end{abstract}

palavras-chave:

café; design-informacional; tipografia; cores; embalagem

Espaço reservado para organização do congresso.

\footnotetext{
${ }^{1}$ http://lattes.cnpq.br/1936812449121252

2 http://lattes.cnpq.br/6513053455487767

${ }^{3}$ http://lattes.cnpq.br/8935299354649314

4 ttp://lattes.cnpq.br/1114262566532633
} 


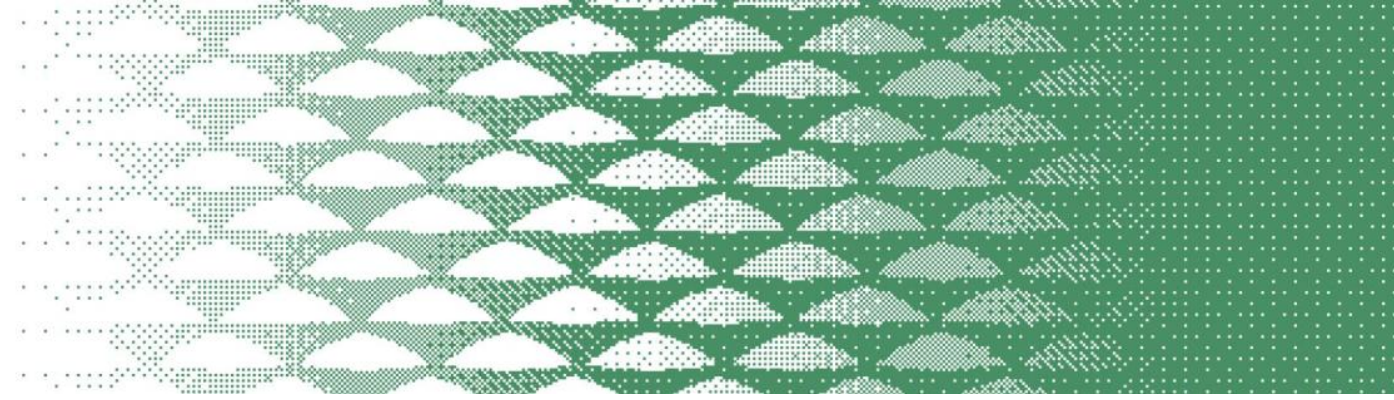

\section{Introdução}

Quando entramos no assunto de café, observa-se que é evidente ser este um tema posicionado em várias áreas, tais como econômica e histórica, bem como em diversos veículos de comunicação. Nesse artigo, o café será abordado como uma fonte de pesquisa de mercado, ou seja, sob a ótica de empresas que fazem sucesso em meio ao comércio em São Luís - MA. Também será explorada a questão do design, em relação à embalagem, a ser analisada como meio de identificação de conteúdo e comunicação visual.

O Design é algo muito amplo a ser explorado; são muitas áreas, e grande parte delas interligadas. Neste particular, a comunicação visual proporciona uma visão geral, desde símbolos e cores até a tipografia do produto, ou seja, o formato das letras que, nessa fusão geram a identificação. A embalagem, por sua vez, é um ponto fundamental para uma empresa ou marca conseguir decolar seu produto dentro do mercado.

Tal entendimento, tomando como referência o produto café, especificamente em São Luís do Maranhão, será abordado neste artigo, onde será explorada a colocação da comunicação visual dentro da área do design de embalagens e ao público consumidor, propondo analises de embalagens de empresas concorrentes, bem como a exploração da temática de design focando em cores, tipografia e afins. Tais abordagens objetivam entender melhor a comunicação proposta em diversas embalagens associadas a variedades de conteúdos distintos.

O café é a segunda bebida mais utilizada no Brasil, depois da água. Em 1996, o Brasil alavancou o primeiro lugar no mundo na sua produção, e a partir de 2004, o seu consumo tem passado por um ritmo de crescimento surpreendente, ganhando cada vez mais adeptos, de acordo com levantamento da pesquisa da ABIC em 2005.

\section{Elementos gráficos}

A literatura (Santos Neto, 2001; Mestriner, 2007; Stewart, 2007; Dupuis e Silva, 2008; Giles, 2009), aponta que os elementos visuais das embalagens são definidos pelos principais elementos que determinam o projeto gráfico-informacional, organizados em oito tópicos, a seguir:

1. Identidade visual de marca: compreende a assinatura visual da marca principal - termo que designa a combinação de logotipo (a configuração visual do nome da empresa ou produto) e o símbolo, quando houver; a assinatura visual do produto e o descritivo do produto, incluindo os padrões de projeto que formam a identidade;

2. Imagens: compreendem ilustrações bidimensionais, tridimensionais e fotografias;

3. Cor: matiz, valor e intensidade, modelos cromáticos e interação cromática são os atributos e conhecimentos necessários para a criação de paletas cromáticas, que podem ser utilizadas para a identidade visual de uma marca, para identificar e segmentar versões de produtos e para atribuir hierarquia à informação disposta na embalagem;

4. Famílias tipográficas: uniformidade estilística, espacejamentos, organização, hierarquia por meio do posicionamento, tamanho, peso, contraste e estrutura óptica interferem na legibilidade e leiturabilidade das informações. Além disso, a tipografia também é responsável pela diferenciação, linguagem e comunicação do posicionamento de um produto em sua embalagem; 
5. Elementos decorativos: compreendem sistemas de apoio, grafismos, contornos decorativos e outros possíveis elementos gráficos que, em geral, cumprem uma função prioritariamente estética na embalagem;

6. Símbolos e pictogramas: símbolos, ícones e pictogramas podem transmitir a informação de uma maneira rápida e objetiva, utilizados para explicar as características e benefícios de um produto, as instruções de uso, para advertir ou ainda para facilitar a compreensão da informação em diferentes idiomas;

7. Código de barras, pesos e medidas: além de informações obrigatórias específicas a cada categoria de produtos. Esses são elementos que precisam ser contemplados no projeto gráfico, seguindo às normas vigentes e estabelecendo as relações de contraste necessárias para a leitura do código;

8. Tabelas e quadros: elementos auxiliares à disposição das informações, obrigatórias (como tabelas nutricionais para alimentos) ou não, que podem contribuir para a hierarquia visual, organização ou para dar destaque a determinado texto.

O desenho, a seleção e a composição destes elementos determinarão a eficiência e a eficácia do projeto gráfico de uma embalagem e, para tanto, o uso de princípios de geometria e ergonomia visual e informacional contribui para a coerência formal e a qualidade gráfico-visual da solução.

\section{Metodologia}

A metodologia apresentada nesse documento é a Metodologia de Mijkseenar (1997), que a elaborou através de uma adaptação variáveis de elementos gráficos, definidas por Bertin (1986). Segundo Mijksennar (1997), diferentes elementos gráficos podem ser utilizados para reforçar a transmissão de informações visuais. Ele definiu tais elementos em duas categorias principais: as de diferenciação, que indicam distinção de tipos, expressas a partir do uso de cores e formas, e as hierárquicas, que indicam diferença de importância, utilizando tamanho e intensidade. Ele também definiu elementos de apoio, tais como áreas de cor, linhas e blocos, que possuem a função de organizar e acentuar as informações. Neste trabalho daremos ênfase às categorias de diferenciação e hierarquia.

Quadro 1 - Análise Metodológica - Mijkseenar

\begin{tabular}{ll}
\hline Diferenciação & Cor \\
Classifica de acordo com & Ilustrações \\
a categoria e o tipo & Largura de Coluna \\
& Fonte tipográfica \\
\hline Hierarquia & Posição sequencial (cronologia) \\
Classifica de acordo com & Posição na página (layout) \\
a importância & Tamanho da fonte \\
& Peso da fonte \\
& Espaçamento de linhas \\
\hline Apoio & Áreas de cores e sombras \\
& Linhas e blocos \\
& Símbolos, jogos, ilustrações, atributos do texto (itálico, etc.)
\end{tabular}




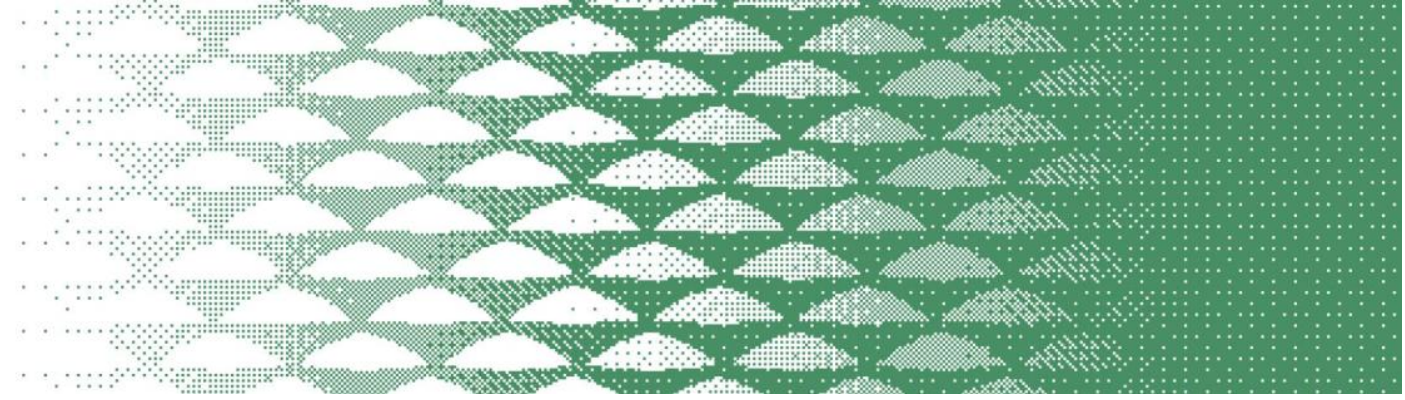

Fonte: adaptado de Mijkseenar (1997)

\section{Resultados e discussões}

Nesse tópico será apresentada a comparação entre três produtos de marcas distintas de variantes de café sendo, estes: clássico, descafeinado e extraforte. A pesquisa será baseada na metodologia de Mijkseenar (1997), conforme o quadro acima, porém focando somente em dois itens: a parte da diferenciação, que remete a análise de cores e ilustrações, e a parte de hierarquização, que remete a à tipografia e seus elementos.

\section{Quadro 2 - análise cores vermelho e azul da embalagem}

CORES

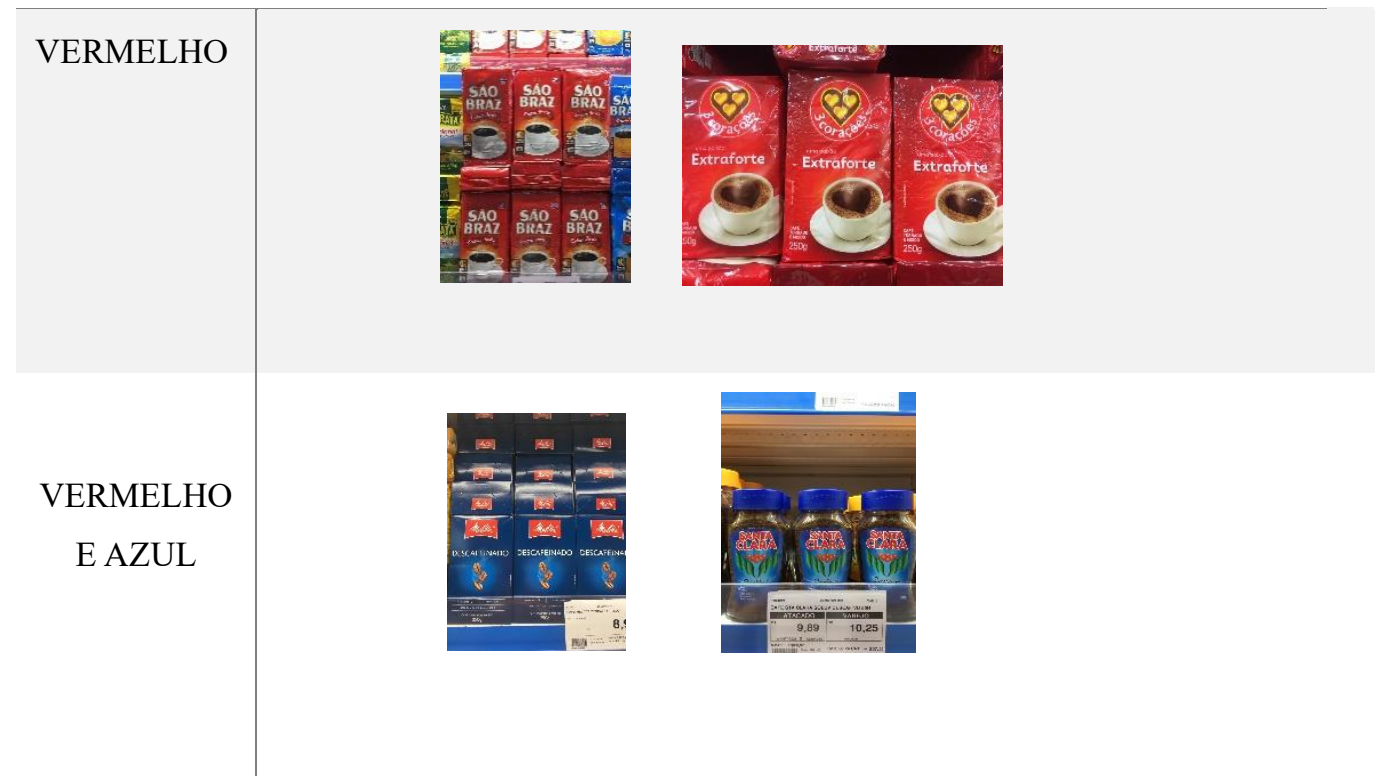

Conforme a colocação desses quadros, é perceptível que na segunda categoria a cor dominante é o azul, enquanto o vermelho é somente cor de destaque para a fonte da letra das outras embalagens. As embalagens vermelhas representam a variante de café extraforte e as azuis a variante descafeinado. Segundo Patel (2021), a cor vermelha remete muito à paixão, mas também remete à questão da força, já que é uma das grandes predominantes na paleta do marketing. O azul, por sua vez, representa à confiança, lealdade e segurança. Trazendo para o contexto do café, como o vermelho é uma cor dominante e sua variante é extraforte, a cor foi colocada para dar representação à variante, e propositalmente chamar a atenção do cliente. Enquanto na embalagem azul, ela dá destaque para se sobressair, da mesma forma que na outra embalagem o azul segue representando uma variante distinta. 


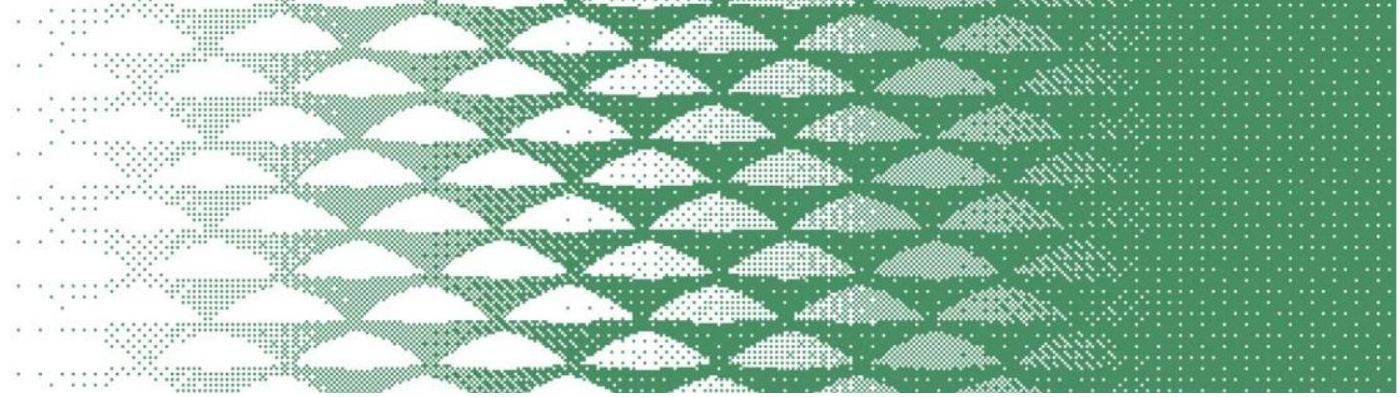

Quadro 3 - análise cores amarelo e verde da embalagem

CORES

\begin{tabular}{l|ll}
\hline AMARELO & & \\
AMARELO & E VERDE & \\
&
\end{tabular}

Esse quadro mostra dois modelos tradicionais representados na cor amarelo e com alguns detalhes verdes. Patel (2021) fala que no marketing o amarelo representa positividade, alegria, diversão, entre outros sentimentos positivos, enquanto o verde é visto como uma cor que representa algo relacionado à natureza e saúde, e se iguala até na parte de lealdade, que bate com o azul. O amarelo é colocado para dar claridade, e chama a atenção do freguês propositalmente. O verde, por sua vez, é muito utilizado para representar produtos que possuem características naturais e sustentáveis, ainda mais em um produto como o café que é derivado de uma plantação. 


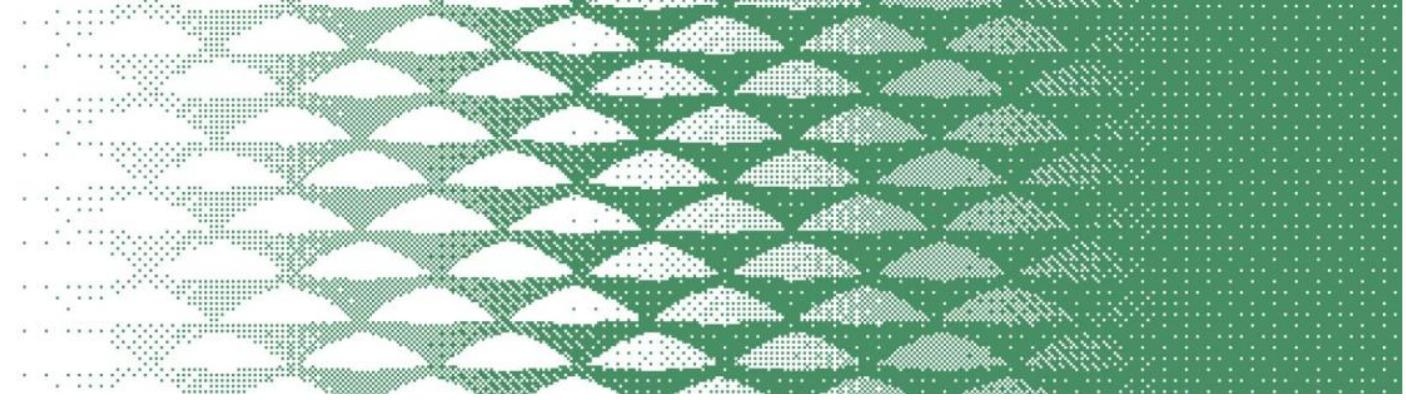

\section{Referências bibliográficas}

ABIC. Disponível em: https://www.abic.com.br/publique/cgi/cgilua.exe/sys/start.htm?sid=38 Acesso em: 16 de março de 2021

ANYADIKE, N - Embalagens Flexíveis: São Paulo: Editora Blucher 2009

BONSIEPE, G.; KELLNER, P.; POESSNECKER, H Metodologia experimental: desenho industrial. Brasília: CNPq/Coordenação Editorial, 1984.CAETANO, Marcela. Consumo de café no Brasil disponível em: https://valor.globo.com/agronegocios/

CERVO, Amado Luiz; BUENO, Clodoaldo. História da Política Exterior do Brasil. São Paulo: Editora Ática, 2002.

CLEMENTE, Matheus. Entenda o que é Psicologia das Cores e descubra o significado de cada cor, 2020. Disponível em: https://rockcontent.com/br/blog/psicologia-das-cores/

DUPUIS, S.; SILVA, J. Package design workbook: the art and science of successful packaging. Beverly, Massachusetts: Rockport Publishers, 2008.

DPASCOAL, Luiz Noberto. Aroma de Café: Guia prático para apreciadores de café. 2. ed. Campinas: Fundação Educar DPaschoal, 2006.

ECCARDI, Fulvio; SANDALJ, Vincenzo. O Café: ambientes e diversidade. Rio de Janeiro, Casa da Palavra, 2003.

FARINA, Modesto, PEREZ, Clotilde, BASTOS, Dorinho Psicodinâmica das Cores. São Paulo: Bluncher 2011

FRANCHETTA, Adriano. A importância da tipografia na construção de uma identidade visual, 2015. Disponível em: https://www.estudioroxo.com.br/

FRASCARA, J. Diseño gráfico y comunicacion. Buenos Aires: Ediciones Infinito, 2000.

GILES, C. O que é design de embalagens? Porto Alegre: Bookman, 2009.

GRACIOSO, Francisco. "Marketing, uma Experiência Brasileira". São Paulo: Cultrix, 1991

GRUENWALD,G Como desenvolver e lançar um produto novo no mercado. São Paulo: Makron Books, 1993.

HELLER, Steven \& DRENNAN, Daniel. The digital designer: the graphic's artist's guide to the new media. New York: Watson-Guptill Publications, 1997.

LUPTON, Ellen \& MILLER, Abbot. Design, writing, research: writing on graphic design. New York: Kiosk Book, Princeton Architetural Press, 1996.

MARCOLINO, Rayane. O cafezinho agora é gourmet, 2014. Disponível em https://www.mundodomarketing.com.br/

MARTINS, Ana Luiza. História do café. 2.ed. São Paulo: Contexto, 2012. 


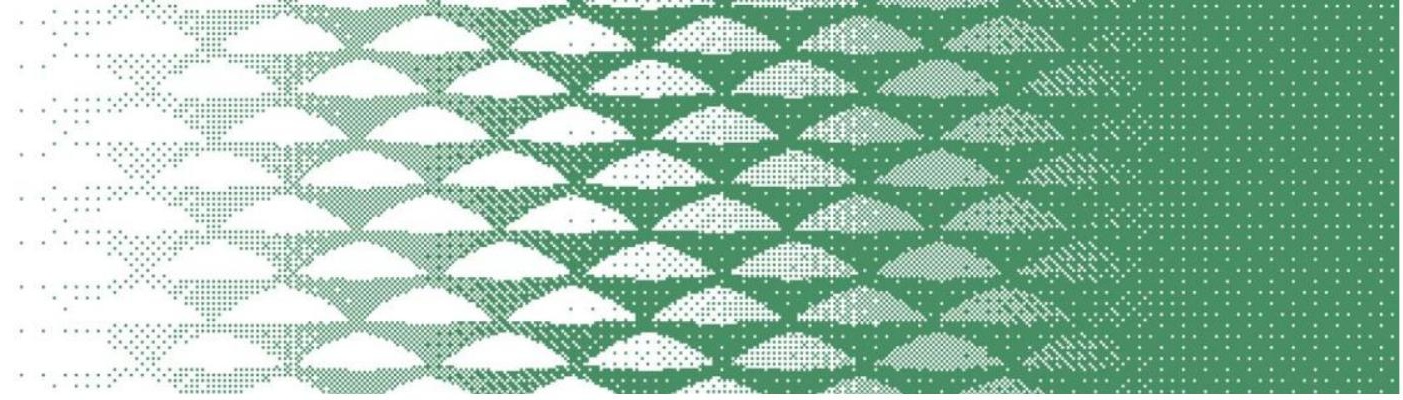

MESTRINER, F. Design de embalagem: curso avançado. Paulo: Pearson Prentice Hall, 2007.

MIJKSEENAR, P. Visual Function: An Introduction to Information Design, Rotterdam: 010 Publishers, 1997.

MORH, Sofia. Café Brasil, 2013. Disponível em: https://www.fonts.com/font/sofia-mohr/cafe-brasil/story

MOURA, R. A.; BANZATO, J. M. Embalagem, unitização e conteinerização, São Paulo, SP: IMAM, 1997.

NARDELLI, Flávio. Curso Viver de Arte, 2020. Disponível em: www.arteemcurso.com.br

NEVES, C. A História do café. Rio de janeiro, Instituto Brasileiro do Café, 1974. NEVES, Orlando. Dicionário da origem das palavras. São Paulo: Oficina do Texto, 2012.

NUNES, Eduardo. A Evolução do Marketing 1.0, 2.0, 3.0 E 4.0, 2020. Disponível em:

https:/ettoscomunica.com/a-evolucao-do-marketing/

38 PATEL, NEIL significado das cores disponível em: https://neilpatel.com/br/blog/significado-da cores/

PEÇANHA, Vitor. 4 Ps do Marketing: entenda tudo sobre o conceito de Mix de Marketing, 2020. Disponível em: https://rockcontent.com/br/blog/4-ps-do-marketing/

RALLO, Rafael. Tipografia: como usar um dos pilares do Design Gráfico a seu favor (2019). Disponível em: https://rockcontent.com/br/blog/tipografia/

SANTOS NETO, L. A. Metodologias de desenvolvimento de embalagem: proposta de aprimoramento para ensino de projeto gráfico. Dissertação (Mestrado em Engenharia de Produção), UF Santa Maria, 2001.

SMITH, Kenneth Louis. Handbook of visual communication: theory, methods, and media. [S.1.]: Routledge, 2005 STEWART, B. Packaging: manual de diseño e producción. Barcelona: Editorial Gustavo Gilli, 2008.

STRUNCK, Gilberto L. Identidade Visual - A direção do Olhar. Rio de Janeiro: Europa, 1989.

TECHLINK. Disponível em http://www.techlink.org.nz/Case-studies/Technologicalpractice/Food-andBiological/Print-PDFs/techlink-tp-smart-choice.pdf. Acesso em: 16 março. 2021

Vânia Marisa Niederauer Flores Severo, Aspectos cognitivos em rótulos: avaliação dos textos informativos em três embalagens de café, 2005

VERMEIREN, L.; DEVLIEGHERE, F.; VAN BESST, M.; KRUIJF, N.; DEBEVERE, J. Developments in the active packaging of food. Trends in Food Science \& Technology, 1999.

ZENFVIA, Marketing de Produto: o que é, como funciona e 5 dicas para melhorar a estratégia, 2019. Disponível em: https://www.zenvia.com/blog/marketing-de-produto 